\title{
Geo-polymerization mechanism and factors affecting it in Metakaolin-slag-fly ash blended concrete
}

\author{
A D Sandeep Kumar ${ }^{1}$, Dinesh Singh $^{2}$, V Srinivasa Reddy $^{3}$, Kaveli Jagannath Reddy ${ }^{4}$ \\ ${ }^{1}$ Research Scholar of Civil Engineering, K L University, Andhra Pradesh, India. \\ ${ }^{2}$ Department of Civil Engineering, K L University, Andhra Pradesh, India \\ ${ }^{3}$ Professor, Department of Civil Engineering, GRIET, Hyderabad., India \\ ${ }^{4}$ B.Tech Student, Department of Civil Engineering, GRIET, Hyderabad, India
}

\begin{abstract}
This paper presents the mechanism and chemistry behind the geo-polymerization and its application in development of Geo-polymer concrete. In this paper, guidelines to develop a geo-polymer concrete is discussed along with the factors affecting the geopolymerization process in concrete. It is concluded that curing temperature, ratio of alkaline liquids, chemical ratio of silicate and sodium in sodium silicate, alkaline liquids / $\mathrm{Si}$-Al source materials ratio, sodium silicate/ hydroxyl ions ratio, presence of calcium, presence of excess water and $\mathrm{Si} / \mathrm{Al}$ ratio in source materials have significant effect on the development of geopolymer concrete and its performance.
\end{abstract}

\section{Introduction}

Production of cement emits high amount of carbon dioxide so always efforts are made to control or reduce or use zero emissions methods to produce cement. Similarly another by-product called fly ash is also produced abundantly in thermal plants so always researchers are evolving new methods to reuse this fly ash in various applications of civil engineering. So 'Davidovits' suggested a method to use fly ash in concrete instead of cement but cement plays the role of binding all the materials in concrete whereas fly ash is not a cementitious material. Then he came up with a process where fly ash is activated and in such way that $\mathrm{Si}$ and $\mathrm{Al}$ ions present in fly ash will react in the presence of alkaline solutions such as sodium silicate and sodium hydroxide or potassium silicate and potassium hydroxide to synthesize into binding material. This process is called geopolymerization because a inorganic polymer type substance is produced with materials of geological origin. The mechanism of polymerization comprises few chemical reactions in the presence of alkaline environment on $\mathrm{Si}$ and $\mathrm{Al}$ minerals present in fly ash resulting in a polymeric chain and ring type inorganic structure. There are various forms of geopolymers such as Phosphate-based geopolymer, Fly ash based Geopolymer, Silico-phosphate based geopolymer and Organic-mineral geopolymer

\section{Geopolymer mechanism}

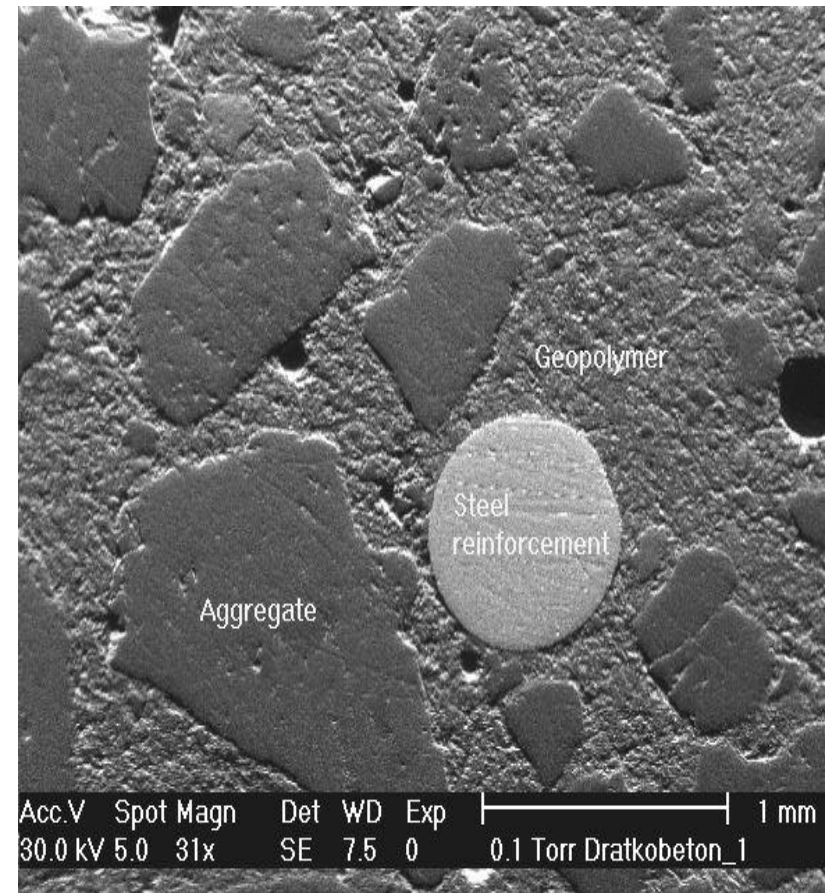

Fig. 1. Geopolymer matrix, coarse aggregate and rebar interface

Alkaline liquids such sodium silicate and sodium hydroxide or potassium silicate and potassium hydroxide dissolve the $\mathrm{Si}$ and $\mathrm{Al}$ atoms present in the fly ash. On application of heat, a gel type structure is formed binding the aggregates 
and any other unreacted constituents of the concrete together to produce a new generation material called 'Geopolymer Concrete'. The chemical process in the geopolymerization activity is essentially $\mathrm{Si}$ and $\mathrm{Al}$ atoms in fly ash, GGBFS, metakaolin etc. will get dissolved in the $\mathrm{OH}^{-}$solution from sodium hydroxide and reorients itself and sets as inorganic polymer under the process of polycondensation.

\section{Constituents of geopolymer concrete}

Any supplementary cementitious material that has mostly Silicon ( $\mathrm{Si}$ ) and Aluminum (Al) mineral ions in fluid form is a potential base material for replacing cement in the geopolymer concrete manufacturing.

\subsection{Fly ash}

Fly ash consists of silicon dioxide $\left(\mathrm{SiO}_{2}\right)$, aluminum oxide $\left(\mathrm{Al}_{2} \mathrm{O}_{3}\right)$, iron oxide $\left(\mathrm{Fe}_{2} \mathrm{O}_{3}\right)$, and calcium oxide $(\mathrm{CaO})$ in the decreasing order of amount present. Low-calcium fly ash or Class F fly ashas per ASTM classification is used as a base material for preparation of geopolymer and is obtained from the Thermal Power Station at Vijayawada, Andhra Pradesh, India.

\subsection{GGBS}

GGBS is added to reduce the setting times of concrete. It has calcium source which will impart setting to the concrete.

\subsection{Metakaolin}

Metakaolin is the source for $\mathrm{Al}$ atoms and also has Si ions abundantly.

\section{$<$}

Sodium silicate $\left(\mathrm{Na}_{2} \mathrm{SiO}_{3}\right)$ and 8 Molar Sodium hydroxide $(\mathrm{NaOH})$ are used as alkaline binders. Sodium silicate is obtained in liquid form from the factory based on the chemical requirement of $\left(\mathrm{Na}_{2} \mathrm{O}=13 \%, \mathrm{SiO}_{2}=26 \%\right.$, $\mathrm{H}_{2} \mathrm{O}=61 \%$ by weight; $\mathrm{SiO}_{2} / \mathrm{Na}_{2} \mathrm{O}=2.0$ by weight) (Rs. 22 per litre). Sodium hydroxide is available in the form of solids or in flaky form of purity $98 \%$ (Rs. 200 per $500 \mathrm{~g}$ ) so to make $\mathrm{NaOH}$ solution, $\mathrm{NaOH}$ solids are dissolved in deionized water for required molarity.

\subsection{Water}

The water content in the geopolymer concrete mixtures was stated by a factor called "water to geopolymer solids ratio" by weight. In this factor, the total weight of water is the sum of water present in the sodium silicate liquid, the water required to make sodium hydroxide solution, and the additional water used to regulate the workability of the geopolymer mixture. Generally the 'water to geopolymer solids' ratio adopted was a constant value of 0.26 .

\section{Mix design}

Assuming the unit-weight of geopolymer concrete as 2400 $\mathrm{kg} / \mathrm{m}^{3}$. The amount of combined aggregates is generally $75 \%$ of the total quantity of concrete.

1. Quantity of combined aggregates $=0.75 \times 2400=1800$ $\mathrm{kg} / \mathrm{m}^{3}(75 \%)$

2. Quantity of fly ash and alkaline liquid $\left(\mathrm{Na}_{2} \mathrm{SiO}_{3}+\right.$ $\mathrm{NaOH})=2400-1800=600 \mathrm{~kg} / \mathrm{m}^{3}$

3. Ratio of alkaline liquid / fly ash by weight $=0.35$ (say)

4. Quantity of fly ash $=600 /(1+0.35)=444 \mathrm{~kg} / \mathrm{m}^{3}$

5. Quantity of alkaline liquids $\left(\mathrm{Na}_{2} \mathrm{SiO}_{3}+\mathrm{NaOH}\right)=600-$ $444=156 \mathrm{~kg} / \mathrm{m}^{3}$

Take the ratio of sodium silicate / sodium hydroxide solution by weight is adopted as 2.5

6. Quantity of $=\mathrm{NaOH}$ solution $=156 /(1+2.5)=45 \mathrm{~kg} / \mathrm{m}^{3}$

7. Quantity of $\mathrm{Na}_{2} \mathrm{SiO}_{3}=(156-45)=111 \mathrm{~kg} / \mathrm{m}^{3}$

Water / geopolymer solids ratio (equivalent to $\mathrm{w} / \mathrm{c}$ ratio) by weight is computed as shown below:

(a) In $\mathrm{Na}_{2} \mathrm{SiO}_{3}$ solution $\left(\mathrm{Na}_{2} \mathrm{O}=13 \%, \mathrm{SiO}_{2}=26 \%\right.$, $\mathrm{H}_{2} \mathrm{O}=61 \%$ by weight),

Water present is $=0.61 \times 111=62 \mathrm{~kg}$ and Solids are $111-62=49 \mathrm{~kg}$

(b) In $\mathrm{NaOH}$ solution, Solids present are $0.262 * 45=$ $12 \mathrm{~kg}$ and the water present is $45-12=33 \mathrm{~kg}$ ( $262 \mathrm{~g}$ of $\mathrm{NaOH}$ pellets are added in $738 \mathrm{ml}$ of water to make one litre of $\mathrm{NaOH}$ solution)

(c) Therefore total weight of water present in alkaline solution $=62+33=95 \mathrm{~kg}$

(d) Weight of geopolymer solids $=444+49+12=505$ $\mathrm{kg}$

Hence Water /Geopolymer solids ratio by weight $=95 / 505$ $=0.19$

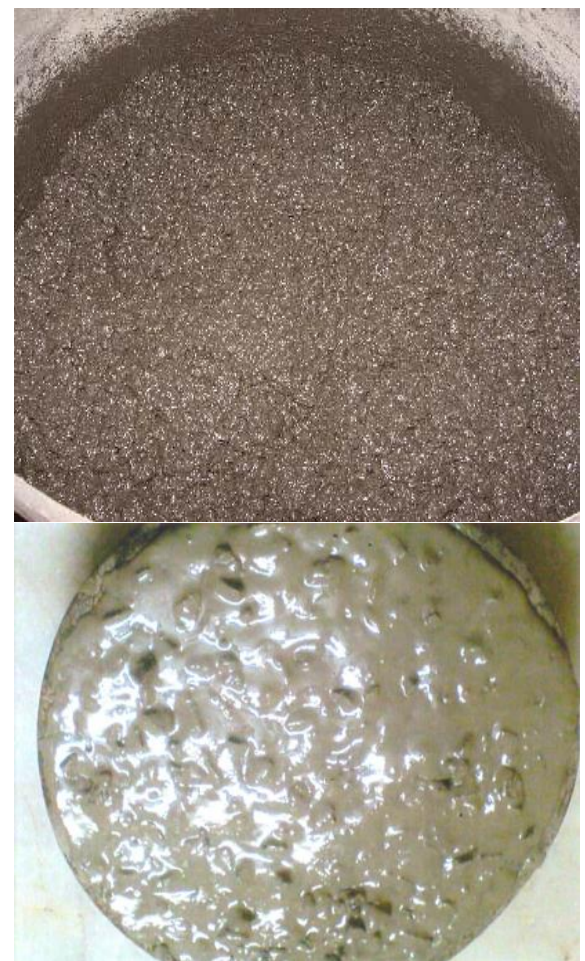

Fig. 2. Freshly mixed Geopolymer Concrete 
Which indicates that the workability of fresh geopolymer concrete is moderate. If desirable, add super plasticizer to the mix to make more workable.

\subsection{Fresh Properties}

The fresh geopolymer concrete will stay workable up to 2 hrs. without any setting and loss of the compressive strength.

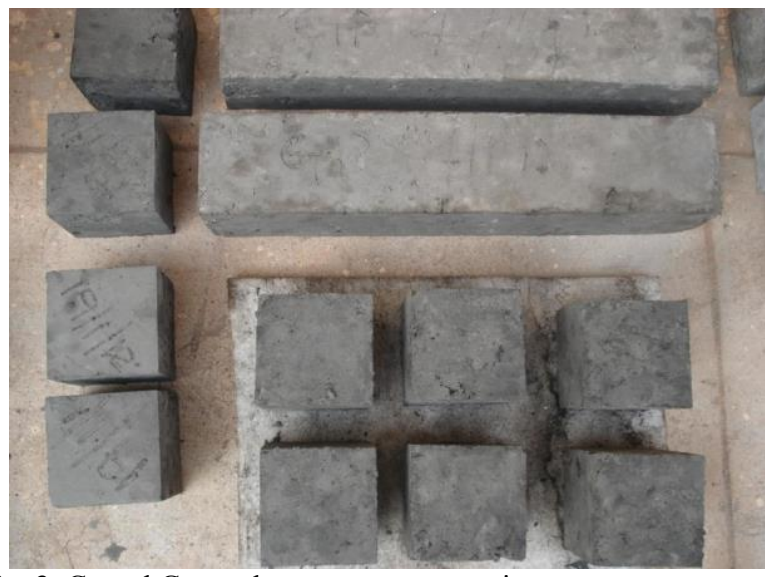

Fig. 3. Casted Geo-polymer concrete specimens

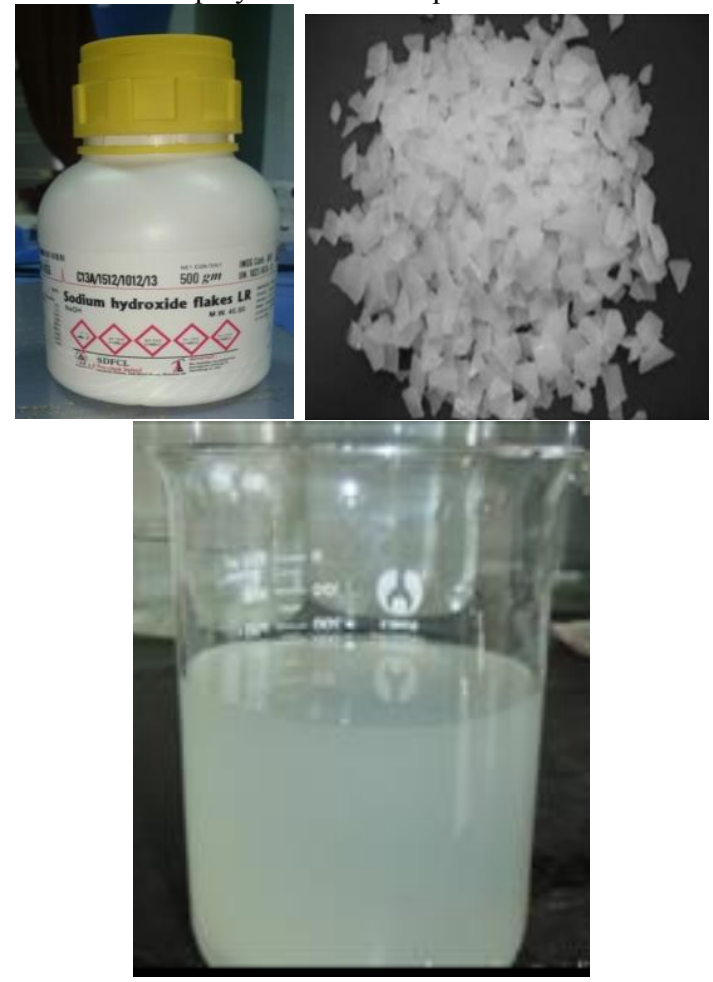

Fig. 4. Sodium hydroxide $(\mathrm{NaOH})$

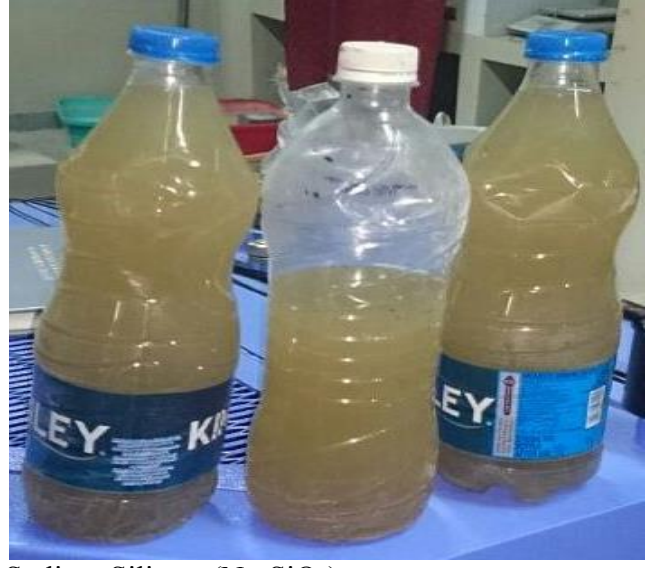

Fig. 5. Sodium Silicate $\left(\mathrm{Na}_{2} \mathrm{SiO}_{3}\right)$

\section{Guidelines to develop Geo-polymer Concrete}

1. Low calcium fly ash is obtained for replacement of cement. In GPC, no hydraulic binder such as cement or lime are used or required.

2. Alkaline activators used are (1) $98 \%$ purity $\mathrm{NaOH}$ in pellet form and (2) $\mathrm{Na}_{2} \mathrm{SiO}_{3}$ having $\mathrm{Na}_{2} \mathrm{O}=13 \%$, $\mathrm{SiO}_{2}=26 \%$ and water $=61 \%$ by weight

3. $\mathrm{NaOH}$ solution is prepared from $\mathrm{NaOH}$ solids ( Calculations are given below)

4. $\mathrm{NaOH}$ solution was prepared one day before and $\mathrm{Na}_{2} \mathrm{SiO}_{3}$ is added to $\mathrm{NaOH}$ just 30 minutes before use in making concrete.

5. Coarse aggregates of size viz., $20 \mathrm{~mm}, 10 \mathrm{~mm}$ ( 60\%:40\% ratio) and river sand as fine aggregate in saturated surface dry condition are used

6. The dry quantities of coarse, fine aggregates along with the fly ash, GGBS and metakaolin were pan mixed for 3 minutes

7. The alkaline liquids are added then and mixed for 3 to 5 minutes more until stiff consistency with glossy appearance is obtained.

8. Cubes are casted and are covered with sheet to prevent water vaporization and were kept at room temperature of 28 degrees Celsius (Ambient temperature) for air dry curing for 28 days and some specimens are oven cures at a temperature of $60^{\circ} \mathrm{C}$ for a period of 24 hours.

9. If specimens are kept in oven immediately (rest period zero) always seal the specimens otherwise if the rest period of $1-3$ days can be given and then keep in oven without seal.

\subsection{Calculation of Alkaline liquids Quantities (example for 8M NaOH)}

Alkaline binders to fly ash ratio is usually assumed as 0.5 based on previous research i.e. $\mathrm{Na}_{2} \mathrm{Sio}_{3}+\mathrm{NaOH} / \mathrm{Fly}$ ash ratio $=0.5$ 
Cement is replaced with fly ash in Geo-polymer concrete so cement quantity is assumed for fly ash quantity. Let us assume cement quantity for M20 grade concrete is $320 \mathrm{~kg}$. So fly ash quantity is $320 \mathrm{~kg}$------- (1)

Then Alkaline binders $\left(\mathrm{Na}_{2} \mathrm{SiO}_{3}+\mathrm{NaOH}\right)$ quantity $=$ Fly ash x $0.5=320 \times 0.5=160 \mathrm{~kg}$------ (2)

The ratio of alkaline liquids are assumed as

$\mathrm{Na}_{2} \mathrm{Si}_{3} / \mathrm{NaOH}=2.5$ for optimum binding.

So to prepare 8 Molar $\mathrm{NaOH}$ solution, $8 \times 40=240 \mathrm{~g}$ of $\mathrm{NaOH}$ pellets or flakes are required to mix in one litre of water. 40 is the molecular weight of the $\mathrm{NaOH}$.

So add 240 grams of $\mathrm{NaOH}$ to $1000 \mathrm{ml}$ of water so the weight of $\mathrm{NaOH}$ solution becomes $1000+240=1240 \mathrm{~g}$ in total.

So in $1240 \mathrm{~g}$ of $\mathrm{NaOH}$ solution, $240 \mathrm{~g}$ is $\mathrm{NaOH}$ and the remaining $1000 \mathrm{ml}$ or $\mathrm{g}$ is water.

To prepare $1240 \mathrm{ml}$ of $\mathrm{NaOH}$ solution, $\mathrm{NaOH}$ pellets required are $240 \mathrm{~g}$ so for $1000 \mathrm{ml}$ of $\mathrm{NaOH}$ solution, the required $\mathrm{NaOH}$ computed as $193.5 \mathrm{~g}$. So $193.5 \mathrm{~g}$ of $\mathrm{NaOH}$ is required to dissolve in $806.5 \mathrm{ml}$ or $\mathrm{g}$ of water to prepare 1L solution of eight molar $\mathrm{NaOH}$.

So, 1litre of 8 molar $\mathrm{NaOH}$ solution contains $193.5 \mathrm{~g}$ of $\mathrm{NaOH}$ flakes or pellets------ (3)

The $\mathrm{Na}_{2} \mathrm{SiO}_{3}$ solution taken as 2.5 litres (Available in market as liquid)

For each $1 \mathrm{~m}^{3}$ of geopolymer concrete, the material calculated is-

Mass of $\mathrm{NaOH}=(320 X 0.5) /(1+2.5)=45.71 \mathrm{~kg}--------(4)$

Mass of $8 \mathrm{M} \mathrm{NaOH}=(45.71 * 193.5) / 806.5=10.96 \mathrm{~kg}$ of $\mathrm{NaOH}$ flakes are added to 34.74 litres of water to make $45.71 \mathrm{~kg}$ of $\mathrm{NaOH}$.

Mass/volume of $\mathrm{Na}_{2} \mathrm{SiO}_{3}=160-45.71=114.29 \mathrm{~kg}$ or 114.29 litres

$\mathrm{Na}_{2} \mathrm{SiO}_{3}=114.29 \mathrm{~kg}$

\section{Factors effecting the polymerization in Concrete (GPC)}

1. Curing Temperature

Generally, optimum temperature for curing is adopted as $60^{\circ} \mathrm{C}$ and period of curing is $24 \mathrm{hrs}$. Studies showed that beyond 24 hrs. period, heat curing is not required. Many researchers opined that longer curing times would increase compressive strength (generally 4 to $96 \mathrm{hrs}$.).

As curing temperature increases compressive strength increases. There is insignificant increase in compressive strength beyond $60^{\circ} \mathrm{C}$ optimum curing temperature $60^{\circ} \mathrm{C}$. Compressive strength increases as temperature of oven curing increases from $30^{\circ} \mathrm{C}$ to $90^{\circ} \mathrm{C}$

2. Molarity of Alkaline liquids

As concentration of sodium hydroxide $(\mathrm{NaOH})$ varies from $8 \mathrm{M}$ to $16 \mathrm{M}$ compressive strength of concrete increases. Since $\mathrm{NaOH}$ is expensive, it is always that $8 \mathrm{M} \mathrm{NaOH}$ is chosen for study and quantities are arrived at based on $8 \mathrm{M} \mathrm{NaOH}$.
16 Molar or 18 Molar $\mathrm{NaOH}$ gives maximum compressive strength but quantity of $\mathrm{NaOH}$ pellets required will be more to prepare high molar solution. Since $\mathrm{NaOH}$ is expensive ingredient in GPC, so always prefer to develop GPC with $8 \mathrm{M}$ $\mathrm{NaOH}$ and accordingly design the GPC mix.

3. $\mathrm{Na}_{2} \mathrm{SiO}_{3} / \mathrm{NaOH}$ Ratio

Higher $\mathrm{Na}_{2} \mathrm{SiO}_{3} / \mathrm{NaOH}$ (2.0 to 3.5) higher compressive strength but research shows that $\mathrm{Na}_{2} \mathrm{Sio}_{3} / \mathrm{NaOH}$ ratio of 2.5 is optimum. Maintain $\mathrm{Sio}_{2} / \mathrm{Na}_{2} \mathrm{O}$ in the preparation of Sodium silicate $=2.00$ (Research shows that $\mathrm{SiO}_{2} / \mathrm{Na}_{2} \mathrm{O}$ in sodium silicate can be between 2.00-2.40)

4. Aggregates

It can be understood that only the binder (which usually occupies around 20 to $25 \%$ of total mass) is different in geopolymer concrete when compared to OPC concrete. Therefore, the effects of properties and grading of aggregates were not investigated in this study.

5. Preparation of Alkaline binders solution

Generally alkaline liquids are prepared by mixing of the sodium hydroxide solution and sodium silicate solution at the room temperature. When the solution mixed together the both solution start to react that is polymerization takes place. It liberates large amount of heat so Alkaline chemicals are mixed before 30 minutes of concrete making. Many researchers opined that it should be mixed 1 day before using in concrete. Sodium silicate should be added before $30 \mathrm{~min}$ of concrete making to Sodium hydroxide. But Sodium hydroxide should be prepared one day before. It is strictly suggested that the $\mathrm{NaOH}$ solution must be ready 24 hours prior to use and also beyond 36 hours $\mathrm{NaOH}$ becomes into semi-solid liquid. So the prepared solution should be used within this time.

6. Setting times

Initial setting of geopolymer is very high, so GGBS should be added to reduce setting time. Only with fly ash, addition will not set for even 2 days. Adding metakaolin will improve the process of polymerization because in metakaolin, aluminates are abundantly available. Silicate and Aluminates are essential requirements for polymerization.

7. Rest Period

Rest period is the period before keeping in oven for curing. Always seal and keep it in oven or allow rest period of 1 - 3 days and keep in oven without seal.

8. Alkaline liquids type

$\mathrm{NaOH}$ /or $\mathrm{KOH}$ and $\mathrm{Na}_{2} \mathrm{SiO}_{3}$ /or $\mathrm{K}_{2} \mathrm{SO}_{3}$ are the alkaline liquids used. Potassium silicate and hydroxide are very expensive compared to Sodium silicate and hydroxide.

9. $\mathrm{Si} / \mathrm{Al}$ Ratio 
Si-Al source (fly ash, GGBS and metakaolin + silicates ${ }^{+}$water + alkaline liquid forms Geopolymer precursor. Microstructure of geopolymers depends on the ratio of $\mathrm{Si} / \mathrm{Al}$. For geopolymer concrete it is assumed $\mathrm{Si} / \mathrm{Al}$ ratio to be 2.0 , for use of geo-polymers for making bricks or ceramics or fire refractory tiles $\mathrm{Si} / \mathrm{Al}$ ratio should be maintained to 1 , to prepare geopolymer sealants $\mathrm{Si} / \mathrm{Al}$ ratio should be greater than 3.0.

\section{Water}

Water will be freed from the geopolymer matrix throughout chemical reactions. This water unbound from the geopolymer matrix makes discontinuous nano level pores in the matrix which are helpful to the performance of geo-polymers.

11. $\mathrm{pH}$ value

In ordinary Portland cement concrete has high alkalinity i.e. high $\mathrm{pH}$, this feature is advantageous to concrete embedded with rebars because high alkaline environment will create a passive layer on the surface of the steel reinforcement preventing them from corrosion where as in in Geopolymer concrete, high alkalinity is deleterious to tits performance .

12. Fly ash Class

Fly ash must be finer to enhance its reactivity. Subbituminous coal on burning produces fly ash with calcium content more than $20 \%$ and less percentage of iron whereas bituminous coal and anthracite coal produces fly ash with less than $10 \%$ calcium and more percentage of iron. Existence of high percentage of calcium effects the polymerization process and consequently its microstructure.

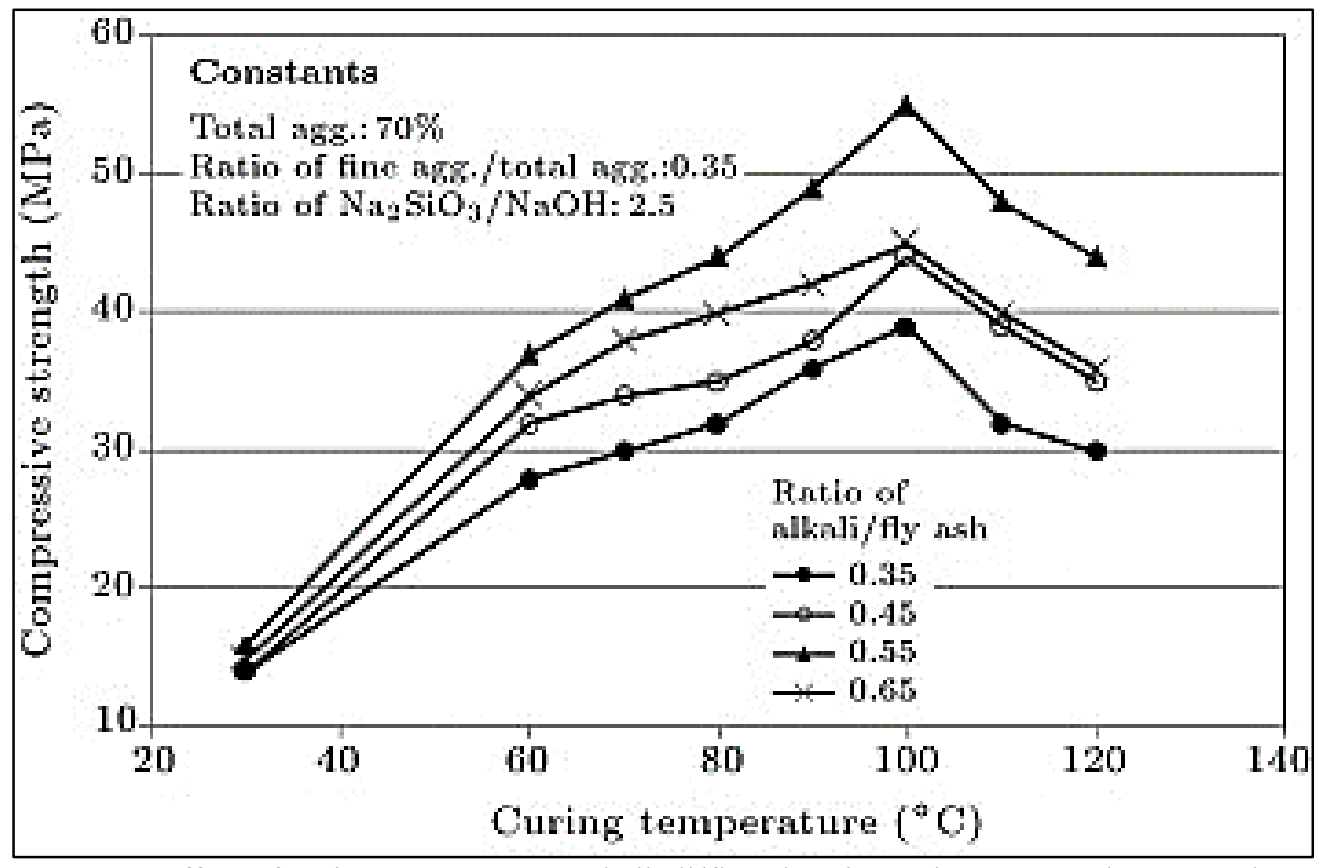

Fig. 6. Effect of curing temperature and alkali/fly ash ratio on the compressive strength

\section{Conclusions}

This study summarizes the factors effecting the geopolymerization and mechanism behind it as follows-

1. Generally, optimum temperature for curing is adopted as $60^{\circ} \mathrm{C}$ and period of curing is $24 \mathrm{hrs}$.

2. Always prefer to develop GPC with $8 \mathrm{M} \mathrm{NaOH}$ and accordingly design the GPC mix.

3. Maintain $\mathrm{Sio}_{2} / \mathrm{Na}_{2} \mathrm{O}$ in the preparation of Sodium silicate $=2.00$

4. It is strictly suggested that the $\mathrm{NaOH}$ solution must be ready 24 hours prior to use and also beyond 36 hours $\mathrm{NaOH}$ becomes into semi-solid liquid. So the prepared solution should be used within this time.
5. Initial setting of geopolymer is very high, so GGBS should be added to reduce setting time. Only with fly ash, addition will not set for even 2 days. Adding metakaolin will improve the process of polymerization because in metakaolin, aluminates are abundantly available. Silicate and Aluminates are essential requirements for polymerization.

6. Always seal and keep it in oven or allow rest period of 1- 3 days and keep in oven without seal.

7. Si-Al source (fly ash, GGBS and metakaolin + silicates + water+ alkaline liquid forms Geopolymer precursor. For geopolymer concrete it is assumed $\mathrm{Si} / \mathrm{Al}$ ratio to be 2.0 . 
8. Fly ash with less than $10 \%$ calcium and more percentage of iron is best to use because the existence of high percentage of calcium effects the polymerization process and consequently its microstructure.

\section{References}

1. Aiad, Influence of time addition of superplasticizers on the rheological properties of fresh cement pastes, Cem Concr Res 33 (2003) $1229-1234$.

2. C. P. E. Bedard, and N. P. Mailvaganam, The use of chemical admixtures in concrete: Part II: Admixture-admixture compatibility and practical problems, ASCE Journal of Performance of Constructed Facilities (2005) 263-266.

3. S. Chandra, Bjornstrom, Influence of Cement and Superplasticizer type and dosage on the fluidity of cement mortars, Cem Concr Res 32 (2002) 1613 1619.

4. Tummala Suresh Kumar, Kosaraju Satyanarayana, Materials Today: Proceeding, 26 (2), 3228-3233, (2020)

5. M. Collepardi, Admixtures used to enhance placing characteristics of concrete, Cem Concr Compose 20 (1998) 103-112.

6. E. Hanna, M. Ostiguy, K. Khalifé, O. Stoica, B.-G. Kim, C. Bédard, M. Saric- Coric, M. Baalbaki, S. Jiang, P.C. Nkinamubanzi, P.C. A?tcin, and N. Petrov, The importance of superplasticizers in modern concrete technology, CANMET/ACI International conference on superplasticizers and other chemical admixtures in concrete, ACI SP (2000).

7. Suresh Kumar Tummala, Dhasharatha G, E3S Web of Conferences 87, 01030 (2019)

8. Papayianni, G. Tsohos, N. Oikonomon, P. Marira, Influence of superplasticizer type and mix design parameters on the performance of them in concrete mixtures, Cem Concr Compose 27 (2005) 217222.

9. M. Yousuf, A. Mollah, P. Palta, T. R. Hess, R. K. Vempati and D. L. Cocke, Chemical and physical effects of sodium lignosulfonate superplasticizer on the hydration of portland cement and solidification/stabilization consequences, Cem Concr Res 25 (1995) 671-682. 